\title{
“Unusual brain stone": heavily calcified primary neoplasm with some features suggestive of angiocentric glioma
}

\author{
Jahangir Sajjad, MBBS, MRCS, ${ }^{1}$ Chandrasekaran Kaliaperumal, FRCSI, FRCSEd(NeuroSurg), ${ }^{1}$ \\ Niamh Bermingham, FRCPath, ${ }^{2}$ Charles Marks, FRCS,${ }^{1}$ and \\ Catherine Keohane, FRCPath, FFPath, FRCPI ${ }^{2}$
}

Departments of ${ }^{1}$ Neurosurgery and ${ }^{2}$ Neuropathology, Cork University Hospital, Cork, Ireland

\begin{abstract}
This 40-year-old man presented with a 5-month history of progressive right-sided headache associated with visual blurring. He also had a history of epilepsy but had been seizure free with medication for the past 10 years. An initial CT scan of his brain performed 16 years previously had revealed a small area of calcification in the right parietal region. In the current presentation, he had a left-sided homonymous hemianopia but no other neurological deficits. A CT scan of his brain showed a much larger calcified, partly cystic lesion in the right parietal region. Because he was symptomatic, the lesion was excised and the cyst was drained. Histological examination of the excised tissue showed an unusual primary tumor that was difficult to classify but had some features of angiocentric glioma. The heavy calcification, mixed-density cell population, and regions with features of angiocentric glioma were most unusual. The patient remained asymptomatic 5 years after surgery, and follow-up scans did not show recurrence.
\end{abstract}

http://thejns.org/doi/abs/10.3171/2014.11.JNS131158

KEY WORDS brain tumor; angiocentric glioma; intracranial calcification; oncology; epilepsy

$\mathrm{N}$ EOPLASMS with a mixed glioneuronal cell population are relatively uncommon and account for less than $1 \%$ of all brain neoplasms. ${ }^{10}$ Histologically, they are a diverse group, which has been expandedlargely due to improved immunohistochemical methods - to include newly recognized uncommon entities, such as papillary glioneuronal tumor, glioneuronal tumor with neuropil rosettes, dysembryoplastic neuroepithelial tumor (DNET), and rosette-forming glioneuronal tumor of the fourth ventricle, ${ }^{8}$ in addition to the more common and longer-recognized gangliogliomas. These lesions are often identified in adolescents with seizures, appearing on imaging as calcified low-grade and sometimes partly cystic masses ${ }^{8,10}$ Angiocentric glioma is a relatively recently recognized low-grade usually supratentorial tumor of children or young adults associated with drug-resistant seizures and with a good prognosis. ${ }^{8,13,19}$ Its cell of origin is uncertain, but it may derive from astrocytic, ependymal, radial glial, or neuronal elements. ${ }^{6}$ It is not usually associated with dense calcification. It has very rarely been described as part of a mixed glioneuronal neoplasm, ${ }^{6}$ although whether the neuronal population represents residual cortical "trapped" neurons is uncertain. In the case reported here, the patient presented with seizures at the age of 24 years, and the radiological finding at that time was a small speck of calcification in his brain; his seizures were fully controlled with medication. At his second presentation (16 years later, with headache), imaging revealed a highly calcified large mass with an adjacent cyst. A focally invasive, mixed-cell density tumor was removed; it was found to be composed of both glial and neuronal elements (although the neuronal component was not definitely neoplastic), with a focal perivascular pattern resembling angiocentric glioma. The degree of calcification, infiltra-

ABBREVIATIONS DNET = dysembryoplastic neuroepithelial tumor; EMA = epithelial membrane antigen; WHO = World Health Organization. SUBMITTED September 6, 2013. ACCEPTED November 12, 2014.

INCLUDE WHEN CITING Published online May 29, 2015; DOI: 10.3171/2014.11.JNS131158.

DISCLOSURE The authors report no conflict of interest concerning the materials or methods used in this study or the findings specified in this paper. 
tion of the cortex and meninges, and mixed cell density is most unusual and suggests that an angiocentric glioma pattern may be part of a more complex tumor type. The case also illustrates that "benign" calcification in the brain may need long-term follow-up and imaging surveillance.

\section{Case Report}

History and Presentation

This 40-year-old man presented with a 5-month history of progressive right-sided throbbing headaches. The headaches were constant throughout the day, were relieved by analgesic medication, and resulted in altered sleep pattern. They were not associated with nausea or vomiting. He also complained of recent blurred vision without diplopia. His speech was normal and he had no memory loss. He had a medical history of epilepsy diagnosed when he was 24 years old, and his seizures had been well controlled with sodium valproate for 10 years. A brain CT scan performed at the time of epilepsy onset showed a tiny calcification $(3 \times 3 \mathrm{~mm})$ in the right parietal region without any other abnormality (Fig. 1). He was a smoker (30 pack years) and used to drink 10 units of alcohol per week. There was no relevant family history.

On examination, he had a Glasgow Coma Scale score of 15/15. Cranial nerve examination revealed a left-sided homonymous hemianopia with normal visual acuity and fundoscopic findings. The remainder of the neurological and systemic examinations were normal.

A second CT examination was performed, and this showed a large area of calcification in the right parietal region with associated cystic degeneration $(5 \times 6 \mathrm{~cm})$. There

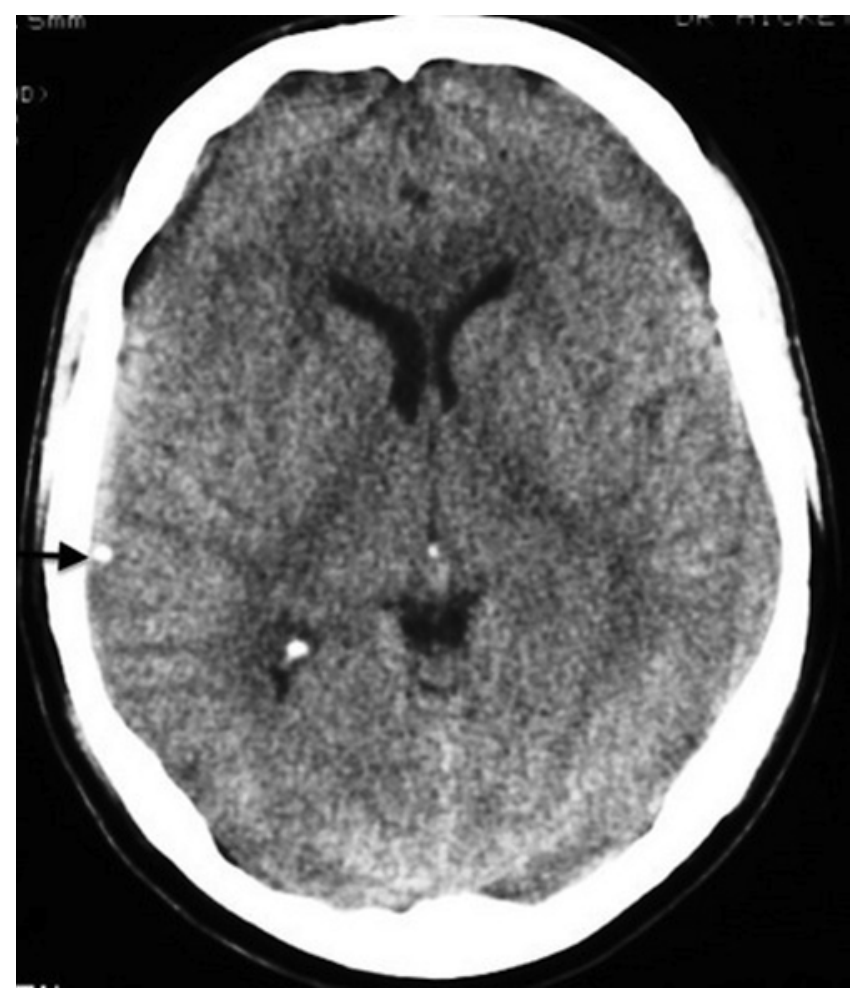

FIG. 1. Image from initial CT scan of the patient's brain showing a tiny calcification (arrow) in the right parietotemporal region. was some mass effect from the lesion but no evidence of hemorrhage (Fig. 2). His routine preoperative investigations were normal. Based on the radiological appearances, the main differential diagnoses were oligodendroglioma and ganglioglioma.

\section{Operation and Outcome}

The patient underwent a right frontoparietal craniotomy. The cyst, which was full of slightly brown fluid, was drained, and the avascular calcified lesion was completely excised. He had an uneventful recovery and was asymptomatic afterward.

Pathological examination showed a very unusual primary tumor, difficult to classify. Macroscopically, the lesion was a nodule of lobulated tan tissue measuring 3.0 $\times 1.9 \times 1.5 \mathrm{~cm}$, with smaller separate fragments, which measured $1.5 \mathrm{~cm}$ in length in aggregate (i.e., when placed next to each other). Microscopic examination showed that the tumor involved the cerebral cortex and focally extended into the overlying subarachnoid space and underlying white matter. There were areas of dense calcium mineralization and areas of reticulin deposition, which were surrounded by areas of reactive fibrillary gliosis, which were strongly positive for GFAP. Much of the lesion appeared low grade and hypocellular with a low MIB-1/Ki-67 cell proliferation index. In some areas, however, there was an infiltrative growth pattern in the cortex, with a prominent perivascular arrangement of cells (Fig. 3A), while other regions showed a more densely cellular solid growth pattern (Fig. 3B). In these latter regions a few cells were in

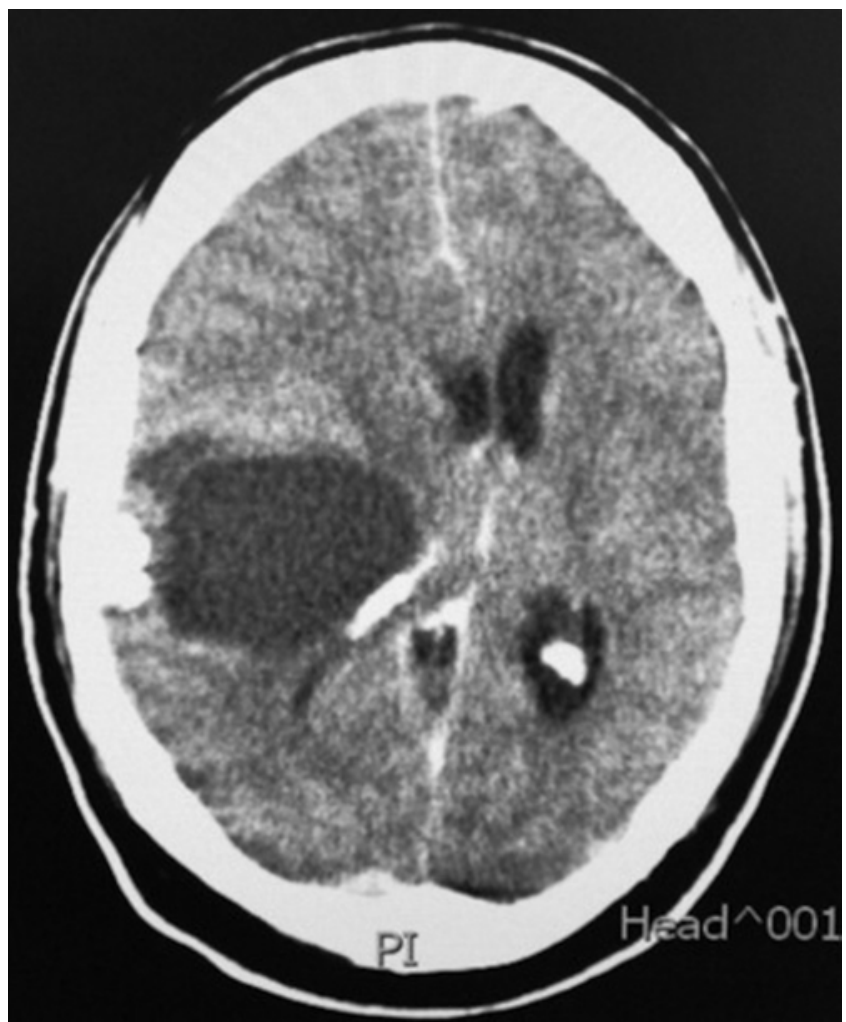

FIG. 2. Image from the CT scan obtained when the patient presented 16 years following his initial evaluation. It shows increased calcification and associated cystic degeneration, causing mass effect. 

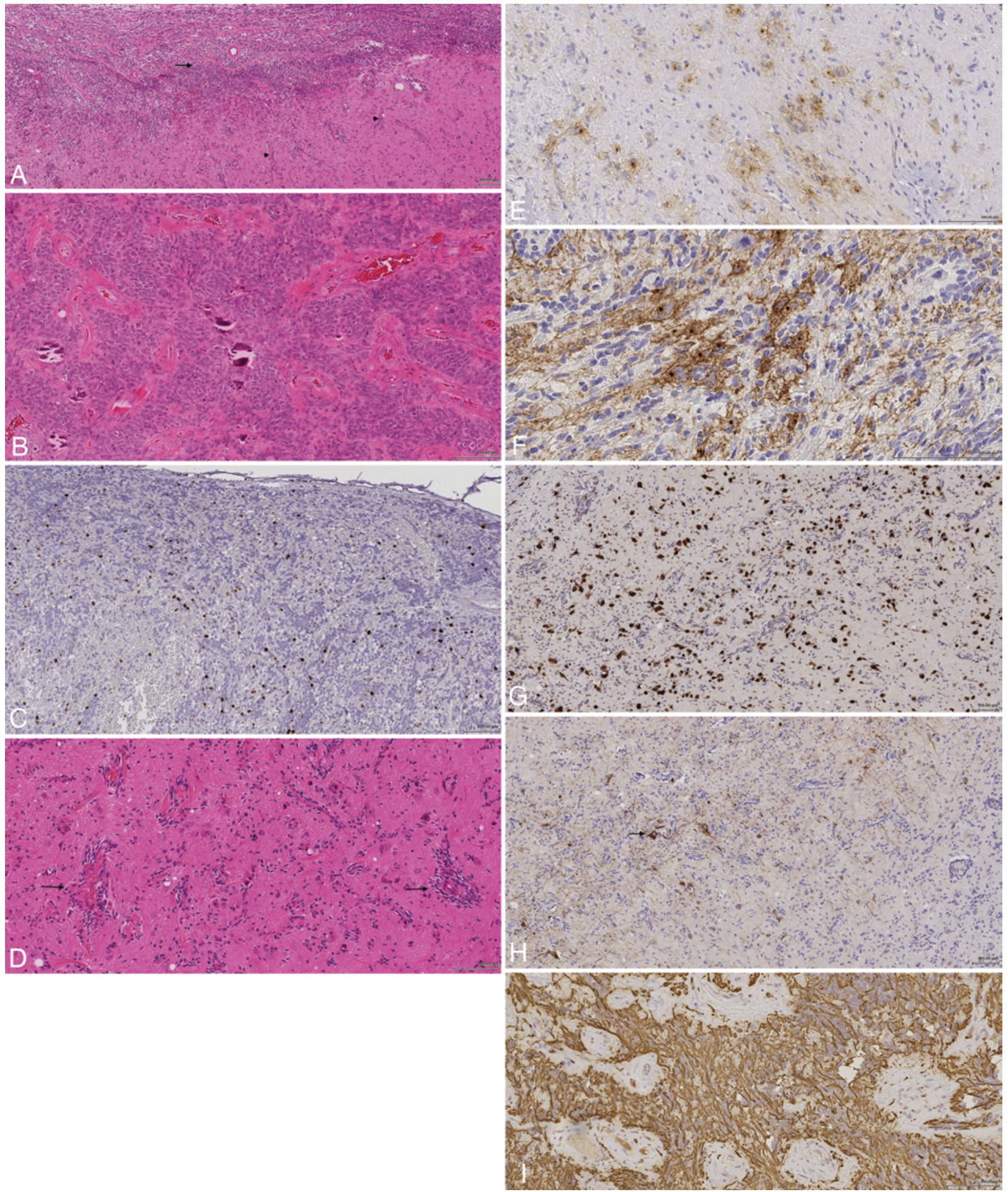

FIG. 3. Photomicrographs obtained at histological examination of the resected lesion. A: Section of the cortical/pial surface of tumor showing subpial infiltration (arrow) and angiocentric pattern (arrowheads). B and C: Example of a densely cellular solid and focally calcified area of the tumor showing increased MIB-1/Ki-67 immunolabeling in the solid region (C). D and E: Sections from a hypocellular region (arrows) of the tumor demonstrating perivascular pattern (D) and a representative example of an area of dot-like EMA positivity (E). F: Example of a hypercellular area that also showed also focal EMA positivity. G: Example of a cluster of NeuN-immunopositive cells within the tumor. H: NF52-immunostained tumor section showing neuronal cells with unusual orientation and morphology (arrows). I: GFAP-immunostained section from a solid area of the tumor showing strong GFAP positivity. Figure is available in color online only. 
mitosis and the MIB-1/Ki-67 labeling reached approximately 5\% (Fig. 3C). Even in the more solid regions, some tumor cells tended to have a perivascular arrangement. Focal staining for epithelial membrane antigen (EMA, which also stains ependymal cells), some in a dot-like pattern, was also present in the tumor cells (Fig. 3E) as well as in hypercellular areas (Fig. 3F). There was also strong immunostaining within the tumor for the neuronal markers synaptophysin, Neu N (Fig. 3G), and NF52 (Fig. 3H). Some tumor cells were GFAP positive (Fig. 3I). Olig2 staining was minimal. In the cortex, morphologically normal nerve cells were visible, possibly representing entrapped neurons, but although unequivocally neoplastic neurons were not seen, clustering of neurons and unusually oriented neurons suggested they were a component of the tumor. The infiltrative growth pattern was against a diagnosis of ganglioglioma. Following further expert opinion on histopathology, the tumor was reported as a glioneuronal neoplasm of uncertain grade with features of angiocentric glioma.

The patient has remained asymptomatic for more than 5 years since surgery, and the 5-year follow-up imaging showed no evidence of tumor recurrence (Fig. 4).

\section{Discussion}

Intracranial calcification is associated with a number of conditions. These can be classified as congenital, physiological, dystrophic, infectious, inflammatory, endocrine, vascular, and neoplastic. In the patient whose case is pre-

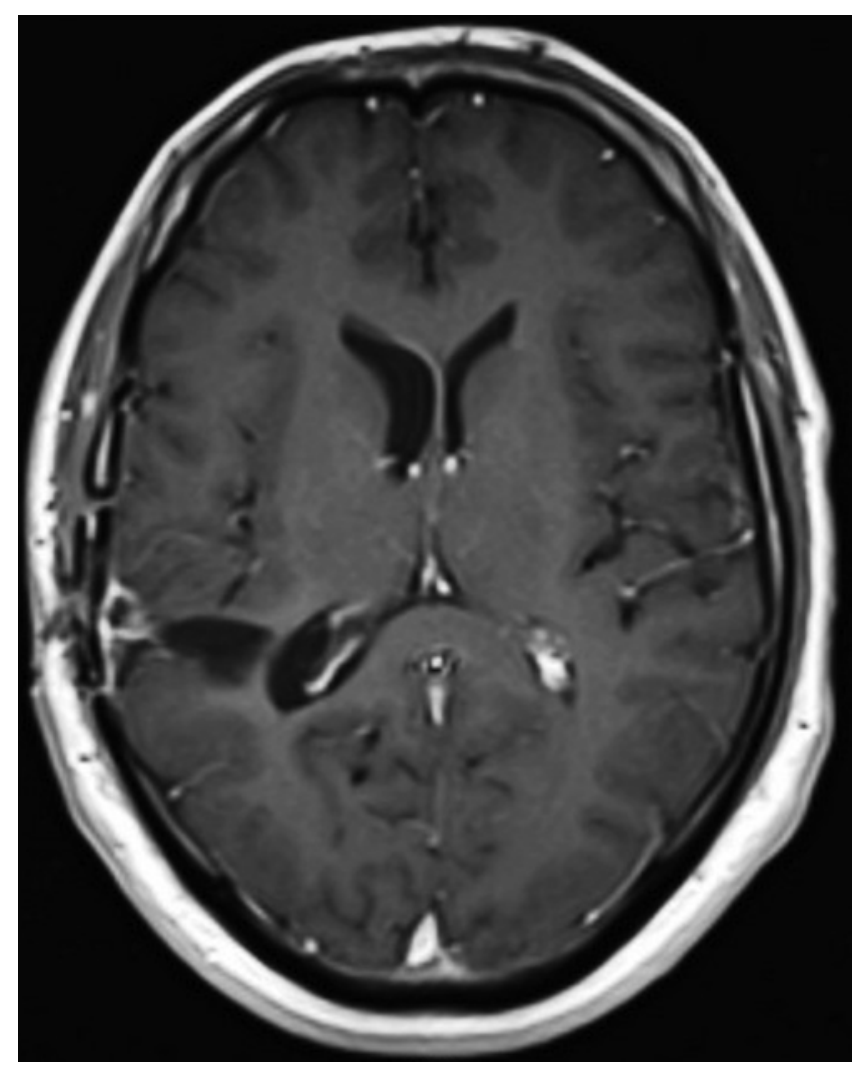

FIG. 4. Axial Gd-enhanced T1-weighted MR image obtained 5 years after surgery showing no evidence of tumor recurrence. sented in this paper, there were no clinical signs of any congenital, endocrine, or metabolic abnormality, and there was no evidence of any infection. The very small region of calcification on the initial CT scan (Fig. 1) and lack of any other associated changes in the brain did not initially favor a vascular or neoplastic cause. He was symptom free for 16 years, and no further investigation was warranted until his second presentation.

The common brain neoplasms associated with intracranial calcifications are oligodendrogliomas $(90 \%), 15,18$ craniopharyngiomas $(40 \%-80 \%),{ }^{3}$ ependymomas $(40 \%-$ $80 \%),{ }^{5}$ pineal tumors $(27 \%-75 \%),{ }^{7}$ central neurocytomas $(69 \%),{ }^{2}$ medulloblastomas (20\%), ${ }^{11}$ and gangliogliomas $(40 \%) .{ }^{20}$ Only a small percentage of DNETs are known to calcify. ${ }^{12}$ Osteogenic sarcoma and lung and breast carcinomas are the most common primary tumors with brain metastases that calcify. ${ }^{16}$

Angiocentric glioma was first described as a separate entity in 2005 and was included in the World Health Organization (WHO) classification of brain tumors in 2007.8,19 Given the recency of the description, information on long-term follow-up of individual cases and the long-term course of these lesions is limited. Although the tumor is regarded as low grade (WHO Grade I) with no recurrence, a recurrent case with glioblastoma-like features has recently been reported. ${ }^{9}$ The densely cellular parts of our patient's tumor with mitoses and increased MIB-1/ Ki-67 labeling suggested cell growth and made grading uncertain, but at 5 years' follow-up there was no evidence of recurrence. An infiltrative pattern is not usual, but has previously been described with angiocentric glioma. ${ }^{6}$ This tumor is typically located superficially in the parietal or temporal cortex.

Angiocentric glioma is rarely associated with calcification. ${ }^{1}$ CT appears to be useful for picking up smaller calcifications, which may be missed by conventional MRI. Susceptibility-weighted imaging appears to be more sensitive for calcification identification than conventional MRI. ${ }^{21}$

In our case, the tumor had a highly unusual histological appearance, making it hard to classify according to the WHO system. The mixed population of cells expressing both neuronal and glial markers, with a prominent angiocentric pattern in part of the lesion, suggests a glioneuronal neoplasm, but whether the neuronal component is truly neoplastic or represents trapped neurons is not certain. Histologically, "pure" angiocentric glioma is classically characterized by diffuse growth and prominent perivascular tumor cell arrangements, with features of astrocytic and ependymal differentiation, including dot-like EMA expression, but without neoplastic neuronal features. ${ }^{13}$ However, Lellouch-Tubiana et al. reported a series with a neuronal cell component in all cases, similar to our case, and thus classified the lesions as mixed glioneuronal neoplasms and proposed the term angiocentric neuroepithelial tumor. ${ }^{6}$ Wang et al. proposed the term monomorphous angiocentric glioma for lesions lacking a neuronal component. ${ }^{19}$ Isocitrate dehydrogenase mutation (IDH1 R132H), is absent in diffuse angiocentric glioma. ${ }^{14}$

Minor calcification has previously been described as a feature of angiocentric glioma, ${ }^{1}$ but the presence of such dense calcification resembling a stone in this case may be 
a consequence of the substantial age of the tumor (at least 16 years). In fact, this case appears to include the longest reported evolution of a tumor with an angiocentric glioma component.

Most angiocentric gliomas are seen in children and young adults with drug-resistant seizures. Shakur et al. reported the median age at tumor surgery in pediatric cases as 6.5 years. ${ }^{17}$ Only a few cases have been reported in which there were no seizures. ${ }^{4}$ In the patient described here, seizures were present 16 years beforehand and were fully controlled with medication. He had headaches and superior hemianopia only at his later presentation, when CT brain changes had progressed. The above-mentioned report of a case with glioblastoma-like features documents a presentation with more obvious neurological deficit in the form of hemiparesis. ${ }^{9}$

Resection of angiocentric glioma cured epilepsy in almost all cases. After resection, patients have been reported to be free from recurrence for up to 6.9 years..$^{13}$ In our case, follow-up MRI 5 years after surgery did not show any recurrence (Fig. 4).

This case demonstrates that an angiocentric glioma pattern can be found in a more complex primary tumor and adds to the list of unusual epilepsy-associated neoplasms. It also indicates the value of long-term follow-up of apparently benign intracranial calcification.

\section{Acknowledgment}

We are very grateful to Prof. David Louis, neuropathologist, Boston, for his opinion on this case.

\section{References}

1. Buccoliero AM, Castiglione F, Degl'innocenti DR, Moncini D, Spacca B, Giordano F, et al: Angiocentric glioma: clinical, morphological, immunohistochemical and molecular features in three pediatric cases. Clin Neuropathol 32:107-113, 2013

2. Chang KH, Han MH, Kim DG, Chi JG, Suh DC, Kim SJ, et al: MR appearance of central neurocytoma. Acta Radiol 34:520-526, 1993

3. Hoff JT, Patterson RH Jr: Craniopharyngiomas in children and adults. J Neurosurg 36:299-302, 1972

4. Hu XW, Zhang YH, Wang JJ, Jiang XF, Liu JM, Yang PF: Angiocentric glioma with rich blood supply. J Clin Neurosci 17:917-918, 2010

5. Koeller KK, Sandberg GD: From the archives of the AFIP. Cerebral intraventricular neoplasms: radiologic-pathologic correlation. Radiographics 22:1473-1505, 2002

6. Lellouch-Tubiana A, Boddaert N, Bourgeois M, Fohlen M, Jouvet A, Delalande O, et al: Angiocentric neuroepithelial tumor (ANET): a new epilepsy-related clinicopathological entity with distinctive MRI. Brain Pathol 15:281-286, 2005

7. Lin SR, Crane MD, Lin ZS, Bilaniuk L, Plassche WM Jr, Marshall L, et al: Characteristics of calcification in tumors of the pineal gland. Radiology 126:721-726, 1978

8. Louis DN, Ohgaki H, Wiestler OD, Cavenee WK, Burger PC, Jouvet A, et al: The 2007 WHO classification of tumours of the central nervous system. Acta Neuropathol 114:97-109, 2007

9. Lu JQ, Patel S, Wilson BA, Pugh J, Mehta V: Malignant glioma with angiocentric features. J Neurosurg Pediatr 11: 350-355, 2013

10. McLendon RE, Provenzale J: Glioneuronal tumors of the central nervous system. Brain Tumor Pathol 19:51-58, 2002

11. Meyers SP, Kemp SS, Tarr RW: MR imaging features of medulloblastomas. AJR Am J Roentgenol 158:859-865, 1992

12. Ostertun B, Wolf HK, Campos MG, Matus C, Solymosi L, Elger CE, et al: Dysembryoplastic neuroepithelial tumors: MR and CT evaluation. AJNR Am J Neuroradiol 17:419430, 1996

13. Preusser M, Hoischen A, Novak K, Czech T, Prayer D, Hainfellner JA, et al: Angiocentric glioma: report of clinicopathologic and genetic findings in 8 cases. Am J Surg Pathol 31:1709-1718, 2007

14. Raghunathan A, Olar A, Vogel H, Parker JR, Coventry SC, Debski R, et al: Isocitrate dehydrogenase $1 \mathrm{R} 132 \mathrm{H}$ mutation is not detected in angiocentric glioma. Ann Diagn Pathol 16:255-259, 2012

15. Reiche W, Grunwald I, Hermann K, Deinzer M, Reith W: Oligodendrogliomas. Acta Radiol 43:474-482, 2002

16. Sastre-Garriga J, Tintoré M, Montaner J, Montalban X, Rovira A, Codina A: [Calcified cerebral metastases. Study of two cases and review of literature.] Neurologia 15:136-139, 2000 (Span)

17. Shakur SF, McGirt MJ, Johnson MW, Burger PC, Ahn E, Carson BS, et al: Angiocentric glioma: a case series. J Neurosurg Pediatr 3:197-202, 2009

18. Vonofakos D, Marcu H, Hacker H: Oligodendrogliomas: CT patterns with emphasis on features indicating malignancy. J Comput Assist Tomogr 3:783-788, 1979

19. Wang M, Tihan T, Rojiani AM, Bodhireddy SR, Prayson RA, Iacuone JJ, et al: Monomorphous angiocentric glioma: a distinctive epileptogenic neoplasm with features of infiltrating astrocytoma and ependymoma. J Neuropathol Exp Neurol 64:875-881, 2005

20. Zentner J, Wolf HK, Ostertun B, Hufnagel A, Campos MG, Solymosi L, et al: Gangliogliomas: clinical, radiological, and histopathological findings in 51 patients. J Neurol Neurosurg Psychiatry 57:1497-1502, 1994

21. Zulfiqar M, Dumrongpisutikul N, Intrapiromkul J, Yousem DM: Detection of intratumoral calcification in oligodendrogliomas by susceptibility-weighted MR imaging. AJNR Am J Neuroradiol 33:858-864, 2012

\section{Author Contributions}

Conception and design: Sajjad. Drafting the article: Sajjad. Critically revising the article: all authors. Reviewed submitted version of manuscript: all authors. Approved the final version of the manuscript on behalf of all authors: Sajjad. Administrative/technical/material support: Bermingham. Study supervision: Marks, Keohane.

\section{Correspondence}

Jahangir Sajjad, Department of Neurosurgery, Cork University Hospital, Wilton, Cork, Ireland. email: jsajjad@me.com. 